\title{
Avaliação microbiológica da linguiça artesanal bubalina produzida na Ilha do Marajó, Pará, Brasil
}

Microbiological evaluation of artisanal sausage produced buffalo on Marajó Island, Pará, Brazil

\author{
A. P. M. Silva ${ }^{1}$; J. N. Bibiano ${ }^{1}$; R. S. Portal ${ }^{1}$; D. R. S. Gonçalves ${ }^{1}$; E. S. B. \\ Araújo $^{1}$; J. C. C. Silva ${ }^{1}$, I. D. L. Neves ${ }^{1}$, E. L. Figueiredo ${ }^{2 *}$ \\ ${ }^{l}$ Graduandos do Curso de Tecnologia de Alimento, Universidade do Estado do Pará, Núcleo Universitário de \\ Salvaterra, 68.860-000, Salvaterra-Pará,Brasil
}

${ }^{2}$ Docente do Curso de Tecnologia de Alimentos, Departamento de Tecnlogia de Alimentos, Universidade do Estado do Pará, 66.095-105, Belém-Pará, Brasil

*lane_figueiredo@yahoo.com.br

(Recebido em 07 de abril de 2016; aceito em 18 de abril de 2016)

\begin{abstract}
A linguiça artesanal bubalina é um alimento tipicamente marajoara, que se enquadra na classe de linguiça frescal. Seu processo de fabricação envolve fatores de risco microbiológico relacionados às suas características intrínsecas e aos fatores externos, como a manipulação inadequada, falta de cuidados higiênicos, bem como tratamento térmico inadequado. Diante disso, o presente trabalho tem como objetivo, analisar a qualidade microbiológica de linguiça artesanal bubalina, elaboradas e comercializadas nos municípios de Soure (Amostra L. S) e Cachoeira do Arari (Amostra L. CA), na Ilha do Marajó, Pará. Foram realizadas análises microbiológicas de Coliformes Totais, Coliformes Termotolerantes, Staphylococcus aureus, contagem padrão de bactérias aeróbias mesófilas, e contagem de fungos filamentosos e leveduras. As determinações microbiológicas foram realizadas em triplicata, seguindo os métodos oficiais de American Public Health Association. De acordo com os resultados microbiológicos, as duas amostras avaliadas apresentaram valores máximos (>1.100 NMP/g) para coliformes totais e termotolerantes. Os níveis de Staphylococcus aureus $\left(5,7 \times 10^{4} \mathrm{UFC} / \mathrm{g}\right.$ para a amostra L. S e $3,8 \times 10^{3}$ UFC/g para a amostra L. CA) estiveram próximos ao limite permitido pela legislação vigente. As mesmas também apresentaram elevada contaminação por bactérias aeróbias mesófilas, fungos filamentosos e leveduras. Dessa forma, pode-se dizer que as amostras de linguiças artesanais bubalinas encontram-se fora dos padrões microbiológicos para embutidos frescais como linguiças cruas e similares, indicando assim falha no controle higiênico-sanitário em seu processo de elaboração.
\end{abstract}

Palavras-chave: Linguiça, Búfalo, Artesanal

The handmade buffalo sausage is a food typically marajoara, which falls under the frescal sausage class. Its manufacturing process involves microbiological risk factors related to their intrinsic characteristics and external factors such as improper handling, lack of hygienic care, and inadequate heat treatment. Thus, the present study aims to analyze the microbiological quality of handmade buffalo sausage, developed and commercialized in the cities of Soure (Sample L. S) and Cachoeira do Arari (Sample L. CA), on the Island of Marajó, Pará. Were held microbiological analysis of Total Coliforms, Coliforms thermotolerant, Staphylococcus aureus, standard count mesophilic aerobic bacteria and fungi count filamentous and yeast. The microbiological determinations were performed in triplicate and following the official methods of the American Public Health Association. According to the microbiological results, the two samples tested showed maximum values (> $1.100 \mathrm{MPN} / \mathrm{g}$ ) for total and fecal coliforms. The levels of Staphylococcus aureus $(5.7 \times 104 \mathrm{CFU} / \mathrm{g}$ for sample L. S and $3.8 \times 103 \mathrm{CFU} / \mathrm{g}$ for sample L. CA) were close to the limit allowed by law. The same also showed high contamination by mesophilic aerobic bacteria and filamentous fungi and yeasts. Thus, it can be said that samples of buffalo handmade sausages are outside the microbiological standards for fresh pork sausage as raw and similar sausages, thus indicating failure hygienic-sanitary control in their development process.

Keywords: Sausage, Buffalo, Handmade 


\section{INTRODUÇÃO}

Os alimentos embutidos são aqueles elaborados com carne ou órgãos comestíveis envoltos por tripa, bexiga ou outra membrana animal [1]. Os principais representantes desse grupo de alimento são as linguiças [2], com destaque para a do tipo frescal, por ser bem aceita e comercializada, devido ao sabor característico e/ou preço acessível [3].

De acordo com a Instrução Normativa n. ${ }^{\circ} 4$ de 31 de março de 2000, da Secretaria de Defesa Agropecuária do Ministério da Agricultura Pecuária e Abastecimento (MAPA), entende-se por linguiça "o produto cárneo industrializado, obtido de carnes de animais de açougue, adicionados ou não de tecidos adiposos, ingredientes, embutido em envoltório natural ou artificial, e submetido ao processo tecnológico adequado" [4].

As linguiças classificam-se ainda de acordo com a técnica de fabricação, podendo tratar-se de um produto fresco, seco, curado e/ou maturado, cozido entre outros [4]. As linguiças frescas, também conhecidas como linguiças do tipo frescal, destacam-se pelo sabor peculiar, preço acessível e questões culturais, como o hábito da população brasileira de consumir alimentos embutidos como salsicha, salame, mortadela, presunto e linguiças. É um dos produtos cárneos mais consumidos no Brasil [5], principalmente devido ao avanço tecnológico, que tem garantido o desenvolvimento de diversos tipos de linguiça, com diferenciação de formas, tamanhos, sabores, valor calórico e preço de mercado [2]. A produção pode ocorrer em estabelecimentos de pequeno, médio e grande porte e, ao processo, agregam-se aditivos utilizados para melhorar os aspectos sensoriais do produto [6]. As características físico-químicas desse alimento devem ser: umidade e gordura máximas de $70,0 \%$ e $30,0 \%$, respectivamente, e quantidade mínima de proteína de $12,0 \%$ [4].

A elaboração da linguiça frescal é rápida e pouco onerosa, e o processo de fabricação até o consumo desse produto envolve fatores de riscos relacionados às suas características intrínsecas e aos fatores externos, como a participação do manipulador de alimentos e estoque do alimento sob temperatura inadequada de refrigeração até a comercialização. Essas circunstâncias servem de alerta à qualidade microbiológica do produto final [7, 8, 9].

A contaminação do alimento por micro-organismos acima dos padrões permitidos pela legislação vigente pode causar danos à saúde do consumidor, o que faz com que a contaminação microbiana assuma destacada relevância para a saúde pública, pelo risco potencial que este tipo de alimento possui de transmitir doenças $[10,11]$.

As prováveis fontes de contaminação para linguiças compreendem as carnes, os envoltórios, os temperos ou condimentos, a manipulação, as máquinas, os utensílios, bem como a água utilizada em todas as operações de limpeza e manutenção [6].

A produção da linguiça envolve várias etapas de manipulação, aumentando assim o risco de contaminação por micro-organismos patogênicos e/ou deterioradores. Além disso, alimentos produzidos artesanalmente, quando elaborados em condições higiênico-sanitárias precárias, ficam mais propícios a contaminação microbiológica, visto a ausência de fiscalização.

A maioria das linguiças produzidas e comercializadas na Ilha do Marajó, são elaboradas utilizando-se a carne bubalina, uma vez que a região Norte, com 820.295 animais, é a que possui o maior quantitativo búfalo. E, das 820.295 cabeças da região Norte, o Pará é o Estado em que se encontra o maior efetivo de bubalinos, com 492.495 mil animais, que responde por $60 \%$ do rebanho dessa região. A Ilha do Marajó representa 62,5 \% do efetivo bubalino do Estado [12].

Esse derivado é produzido de forma artesanal e bastante tradicional, principalmente na culinária marajoara. Diante disso, o presente trabalho tem por objetivo, analisar a qualidade microbiológica de linguiça artesanal bubalina, elaboradas e comercializadas nos municípios de Soure e Cachoeira do Arari, na Ilha do Marajó, no Pará. 


\section{MATERIAL E MÉTODOS}

\section{Coleta das amostras de linguiças artesanais bubalinas}

Para a realização deste trabalho, foram coletadas linguiças artesanais bubalinas, comercializadas em estabelecimentos comerciais (açougue) nos municípios de Soure (codificada como Amostra L.S.) e de Cachoeira do Arari (codificada como Amostra L.CA), na Ilha do Marajó. As amostras foram acondicionadas em sacos plásticos estéreis apropriados, armazenados sob temperatura de refrigeração $\left(7{ }^{\circ} \mathrm{C}\right)$ e encaminhadas para o Laboratório de Microbiologia, do Campus de Salvaterra, da Universidade do Estado do Pará - UEPA.

\section{Análises microbiológicas}

As análises microbiológicas realizadas nas amostras de linguiça foram: Coliformes Totais, Coliformes Termotolerantes, Staphylococcus aureus, contagem padrão de bactérias aeróbias mesófilas, fungos filamentosos e leveduras. As determinações microbiológicas foram realizadas em triplicata, seguindo os métodos oficiais de American Public Health Association - APHA [13].

Utilizou-se $25 \mathrm{~g}$ de linguiça em $225 \mathrm{~mL}$ de solução peptona bacteriológica. Fez-se a homogeneização e preparou-se as diluições entre $10^{-1}$ à $10^{-5}$. A determinação de Coliformes Totais e Coliformes Termotolerantes foi realizada pela técnica do Números mais Prováveis NMP com a série de três tubos múltiplos $\left(10^{-1}, 1\right.$ e 10$)$, em tubos de ensaio e tubos de Durhan. Empregou-se, como meio presuntivo, o Caldo Lauril Sulfato Triptose, com um volume de $8 \mathrm{~mL}$ em cada tubo, seguido da incubação em estufa bacteriológica, sob temperatura de $35^{\circ} \mathrm{C}$, por 24 48 horas. Após leitura, os tubos positivos foram repicados, com auxilio de alça de platina, para Caldo Verde Brilhante bile, a $2 \%$ de lactose, com incubação em estufa bacteriológica, a $35^{\circ} \mathrm{C}$, por 24-48 horas para confirmação da presença de Coliformes Totais, e repicados para Caldo E.C., com incubação em banho maria, sob temperatura de $44{ }^{\circ} \mathrm{C}$, por $24-48$ horas, visando a confirmação de Coliformes Termotolerantes. A detecção de $S$. aureus foi realizada pela técnica de Petrifilm especifico para esta bactéria, com incubação em estufa bacteriológica, sob temperatura de $35^{\circ} \mathrm{C}$, por 24-48 horas. Para a contagem padrão de bactérias aeróbias mesófilas, utilizou-se o Ágar para contagem em placas - PCA, empregando-se a técnica de cultivo em profundidade, e incubação a $35^{\circ} \mathrm{C}$ por $24-48$ horas. E para a contagem de fungos filamentosos e leveduras, utilizou-se o Ágar Potato Dextrose, sob incubação em estufa B.O.D, a $22^{\circ} \mathrm{C}$ por 4 a 5 dias.

\section{RESULTADOS E DISCUSSÃO}

Os resultados das análises microbiológicas nas amostras de linguiças artesanais bubalinas, comercializadas em Soure (Amostra L. S) e Cachoeira do Arari (Amostra L. CA), na Ilha do Marajó, encontram-se na Tabela 1.

Tabela 1: Resultados microbiológicos das amostras de linguiças artesanais bubalina, comercializadas em Soure e Cachoeira do Arari, na Ilha do Marajó

\begin{tabular}{lccc}
\hline \multicolumn{1}{c}{ Análises Microbiológicas } & \multicolumn{2}{c}{ Amostras } & \multirow{2}{*}{ Brasil (2001) } \\
\cline { 2 - 3 } & L. S & L. CA & \\
\hline Coliformes Termotolerantes (NMP/g) & $>1.100$ & $>1.100$ & $5 \times 10^{3}$ \\
Coliformes Totais (NMP/g) & $>1.100$ & $>1.100$ & -- \\
Staphylococcus aureus (UFC/g) & $5,7 \times 10^{4}$ & $3,8 \times 10^{3}$ & $5 \times 10^{3}$ \\
Bactérias aeróbias mesófilas (UFC/g) & $5,1 \times 10^{3}$ & $4,4 \times 10^{5}$ & --- \\
Fungos filamentosos e leveduras (UFC/g) & $9,5 \times 10^{5}$ & $9,0 \times 10^{3}$ & --- \\
\hline
\end{tabular}

De acordo com os resultados obtidos, pode-se verificar nas amostras L. S e L. CA., a presença de coliformes totais e de coliformes termotolerante, que apresentaram valores 
máximos (> 1.100 NMP/g) para estes micro-organismos. Estes valores encontram-se acima do permitido pela Resolução de Diretoria Colegiada - RDC 12, de 02 de janeiro de 2001 [14], que estabelece padrões de $5 \times 10^{3} \mathrm{NMP} / \mathrm{g}$ de coliformes termotolerantes para embutidos frescais, como linguiças cruas e similares. Carne e seus derivados são importantes veículos de transmissão de coliformes termotolerantes, bem como todos os alimentos excessivamente manipulados, como as linguiças. Esse micro-organismo indica contaminação de origem fecal e possível falha higiênico-sanitária na cadeia produtiva [15]. Os coliformes termotolerantes servem como indicador higiênico-sanitário e, quando em níveis inadequados, podem causar danos à saúde do consumidor, causando problemas gastrointestinais, como diarréia, vômitos, febre e dor abdominal [16].

Em linguiças frescais, Cortez et al [17] identificaram coliformes termotolerantes em 73,6 \% de amostras de frango coletadas no estado de São Paulo, enquanto que Chaves et al [18] verificaram esses micro-organismos em 75,0 \% de amostras suínas obtidas no estado do Rio de Janeiro. Alberti; Nava [19] observaram coliformes totais em 100,0 \% das amostras de linguiças frescais independente do tipo de carne. Esses resultados mostram que a deficiência no controle higiênico-sanitário já acontece há alguns anos e ainda permanece no cenário atual.

A legislação vigente não determina o limite mínimo e máximo para Coliformes Totais nesse produto alimentício, no entanto, os resultados demonstraram a elevada contaminação das duas amostras avaliadas (> $1.100 \mathrm{NMP} / \mathrm{g}$ ). Destaca-se que a contaminação por coliformes totais também podem ser minimizadas com a aplicação correta de Boas Práticas de Higiene pelos manipuladores de alimentos, supervisionados pela vigilância sanitária. Esse fato é dificultado em virtude dos açougues não serem rigorosamente inspecionados pela vigilância, sendo esta uma situação relacionada à ineficácia de ações voltadas às capacitações em açougues [20]. No entanto, a contaminação pode também estar relacionada à carne previamente contaminada. No momento do abate, pode haver um extravasamento do conteúdo intestinal do animal, que leva à contaminação da pele e da carcaça do mesmo, que servirá de matéria-prima para derivados cárneos. A carcaça contaminada, ao ser moída para a produção de embutidos, tem sua multiplicação estimulada pelo aumento da superfície de contato. A contaminação microbiana em níveis elevados pode ocasionar doenças transmitidas por alimentos (DTA's). Essas doenças são causadas pela ingestão de alimentos contaminados por um agente infeccioso específico, ou pela toxina por ele produzida, por meio da transmissão desse agente, ou de seu produto tóxico.

Em relação aos resultados de S. aureus, as amostras L. S. e L. CA. apresentaram níveis de $5,7 \times 10^{4} \mathrm{UFC} / \mathrm{g}$ e $3,8 \times 10^{3} \mathrm{UFC} / \mathrm{g}$, respectivamente. A resolução vigente estabelece o limite de até $5 \times 10^{3} \mathrm{UFC} / \mathrm{g}$ de $S$. aureus para embutidos frescais, como linguiças cruas e similares. Dessa forma, pode-se afirmar que a amostra L. S encontra-se acima do permitido por esta resolução, enquanto que a amostra L. CA, apesar de não estar nos níveis acima do permitido, apresentou valores muito próximos ao permitido. $\mathrm{O}$ processo de manipulação nos açougues no momento de estocagem e comercialização pode ser a principal fonte de contaminação por $S$. aureus.

A contaminação por $S$. aureus se torna mais presente pelo fato deste micro-organismo fazer parte da microbiota natural dos homens. O homem e os animais são os principais reservatórios do $S$. aureus, sendo a cavidade nasal seu habitat mais importante e principal veículo de contaminação dos alimentos [21]. A bactéria $S$. Aureus é a maior causadora de intoxicações alimentares no homem, produzindo compostos extracelulares, como as enterotoxinas estafilocócicas, coagulases, nucleases e lipases [22]. Ao avaliar a qualidade microbiológica de linguiças frescais artesanais no estado do Paraná, Souza et al [23] identificou a presença dessa bactéria em todas as amostras avaliadas, sugerindo assim que esses produtos foram excessivamente manipulados. Por outro lado, Neres et al [24] ao avaliar a qualidade microbiológica de diferentes formulações de linguiça bubalina, verificaram resultados microbiológicos satisfatórios, com ausência de $S$. aureus e coliformes termotolerantes, estando assim dentro dos padrões exigido pela legislação.

Segundo Marques et al [25] a intensa manipulação de linguiças associada a carência de Boas Práticas de Fabricação - BPF é um dos principais fatores de risco para contaminação por $S$. aureus. A contaminação é ainda associada às matérias primas e às condições ambientais de produção, visto que pode colonizar superfícies e equipamentos inadequadamente higienizados 
[26]. Esses resultados corroboram com os da presente pesquisa, cuja presença de $S$. aureus em linguiças sugere falta de higiene em sua fabricação e manipulação.

As amostras também apresentaram elevadas contagens de bactérias aeróbias mesófilas e fungos filamentosos e leveduras. Apesar da legislação vigente não exigir as análises desses micro-organismos, as mesmas foram realizadas a fim de fazer um diagnóstico microbiológico mais eficaz. A amostra L. CA $\left(4,4 \times 10^{5} \mathrm{UFC} / \mathrm{g}\right)$ apresentou os maiores níveis de bactérias aeróbias mesófilas, enquanto que a amostra L. S. apresentou os maiores resultados para fungos filamentosos e leveduras $\left(9,5 \times 10^{5} \mathrm{UFC} / \mathrm{g}\right)$.

A linguiça artesanal bubalina por ser um produto embutido, em que a carne é cortada em pequenos pedaços, aumenta a superfície de contato. O processo é executado de maneira manual, tornando esse produto ainda mais suscetível a contaminação microbiológica. É importante ressaltar também que, as linguiças adquiridas para as análises deste trabalho, não foram submetidas a nenhum tratamento térmico anterior, sendo caracterizadas como frescal fator este que contribui para a elevada contaminação dos micro-organismos avaliados.

Apesar de existir em algumas comunidades na Ilha do Marajó, inclusive nos municípios pesquisados, a produção de linguiça submetida ao processo de secagem natural, a mais comumente encontrada e consumida é a linguiça frescal bubalina.

Para ser consumida, a linguiça passa por um tratamento térmico como o assamento. Provavelmente essa temperatura atinge a temperatura de morte da maioria dos microorganismos. Porém o estudo não evidenciou se esta temperatura é suficiente para matar todos esses micro-organismos e toxinas produzidas por eles. Considerando-se que as células de $S$. aureus são termolábeis e facilmente eliminadas por processos moderados de temperatura, as enterotoxinas são termoestáveis e resistentes a temperaturas elevadas [25].

\section{CONCLUSÃO}

O presente estudo constatou que a linguiça artesanal bubalina, produzida no município de Soure (Amostra L. S), na Ilha do Marajó, encontra-se fora dos padrões microbiológicos de coliformes termotolerantes e $S$. aureus, para embutidos frescais como linguiças cruas e similares. Apesar da Amostra L. CA. estar dentro dos limites aceitáveis para S. aureus, esta amostra apresentou alto grau de contaminação para todos os micro-organismos avaliados.

Os resultados apontam como principal causa de contaminação a falta de cuidados higiênicosanitários no processo de fabricação das linguiças, como manipulação inadequada, falta de higiene pessoal, higiene de utensílios e/ou de higiene no momento da elaboração do derivado bubalino. Outro fator limitante para a qualidade microbiológica é o fato de o produto ser cru, não sendo assim submetido a nenhum tratamento térmico até o momento das análises.

A conscientização dos fabricantes se faz necessária, uma vez que a linguiça artesanal bubalina faz parte da tradicional culinária marajoara, sendo amplamente comercializada e consumida nos municípios pesquisados.

\section{REFERÊNCIAS BIBLIOGRÁFICAS}

1. Barbosa L, Madi L, Toledo MA, Rego RA. As tendências da alimentação. In: Brasil Foods Trends 2020. FIESP. Instituto de Tecnologia de Alimentos. São Paulo. 2010. cap. 3, p. 39-48. Disponível em: < http://www.brasilfoodtrends.com.br/Brasil_Food_Trends/index.html>. Acesso em 03/04/2016.

2. Zinnau ER. Desenvolvimento de Linguiças Frescais de Filé de Frango com Queijo e com Azeitona. 2011. 50 f. Relatório de pesquisa. Instituto Federal do Rio Grande do Sul, Bento Gonçalves, 2011.

3. Nascimento RS, Fonseca ABM, Franco RM, Miranda ZB. Linguiças frescais elaboradas com carne de avestruz: característica físico-químicas. Ciência Rural, Santa Maria. 2012; 42(1): 184-188.

4. Brasil. Ministério da Agricultura, Pecuária e do Abastecimento. Instrução Normativa ${ }^{\circ} 4$, de 31 de março de 2000. Aprova os Regulamentos Técnicos de Identidade e Qualidade de Carne Mecanicamente Separada, de Mortadela, de Linguiça e de Salsicha. Diário Oficial [da] República Federativa do Brasil, Brasília, DF.

5. Jesus Junior C, Rodrigues LS, Moraes VEG. Ovinocaprinocultura de corte - a convivência dos extremos. Agroindústria. BNDES Setorial. 2010; 31: 281-320. Disponível em: Acesso em 03/04/2016. 
6. Oliveira MJ, Araujo WM, Borgo LA. Quantificação de nitrato e nitrito em Linguiças do tipo frescal. Ciênc. Tecnol. Aliment. 2005; (25)4;736-742.

7. Medeiros NX. Exposição ao risco microbiológico pela contaminação de linguiças do tipo frescal e salsichas. [dissertação] Mestrado em Ciência Animal - Escola de Veterinária, Universidade Federal de Goiás, Goiânia, 2011. 28 f.

8. Merlinni LS, Begotti IL, Merlini NB, Caetano ICS. Avaliação higiênico-sanitária de linguiças tipo frescal produzidas artesanalmente na região noroeste do Paraná. Centro Científico Conhecer, Goiânia. 2012; 8(15): 344-352.

9. Milani LIG, Fries LLM, Paz PB, Bellé M, Terra NN. Bioproteção de lingüiça de frango. Ciência e Tecnologia de Alimentos, Campinas. 2003; 23 (2):161-166.

10. Catao RMR, Ceballos BSO. Listeria spp., coliformes totais e fecais e E. coli no leite cru e pasteurizado de uma indústria de laticínios, no estado da Paraíba (Brasil). Ciênc. Tecnol. Aliment. 2001; 21(3):281-287.

11. Santos RCD, Rodrigues GA, Caldas FCNL, Oliveira CI, Santos CPW. Avaliação preliminar da qualidade microbiológica de embutidos cárneos artesanais produzidos e comercializados na região metropolitana de Salvador, Bahia, VII CONNEPI, Tocantins, 2012.

12. Figueiredo EL, Lourenço Júnior JB, Toro MJU, Lima SCG. Queijo do Marajó tipo creme: parâmetros físico-químicos e sensoriais. Revista Instituto Laticínios Cândido Tostes. 2011; 378(66): 26-33.

13. APHA - American Public Health Association Compendium of Methods for the Microbiological Examination of Foods. 3 ed. Washington, 2001. 1219 p.

14. Brasil. Ministério da Saúde. Secretaria de Vigilância Sanitária. Resolução RDC no 12, de 2 de janeiro de 2001. Regulamento técnico sobre padrões microbiológicos para alimentos. Diário Oficial da República Federativa do Brasil, Brasília.

15. Gastalho S, Silva GJ, Ramos F. Uso de antibióticos em aquacultura e resistência bacteriana: impacto em saúde pública. Acta Farmacêutica Portuguesa 2014; 3:28-44.

16. Bezerra MVP, Abrantes MR., Silvestre MKS, Sousa ES, Rocha MOC, Faustino JG, Silva JBA. Avaliação microbiológica e físico-química de linguiça toscana no município de Mossoró, RN. Arq. Inst. Biol.. 2012; 79(2): 297-300.

17. Cortez LL, Carvalho ACFB, Amaral LA, Salotti BM, Vidalmartins AMC. Coliformes fecais, estafilococos coagulase positiva (ECP), Salmonella spp. e Campylobacter spp. em linguiça frescal. Alimentos e Nutrição, Araraquara. 2004; 15(3): 215-220.

18. Chaves GMC, Gonçalves PMR, Franco RM, Carvalho JCAP. Avaliação bacteriológica de linguiça frescal suína comercializada no município do Rio de Janeiro. Higiene Alimentar, São Paulo. 2000; 14(13): 48-52.

19. Alberti J, Nava A. Avaliação higiênico-sanitária de linguiças tipo frescal comercializadas a granel por supermercados e produzidas artesanalmente no município de Xaxim, SC. Unoesc \& Ciência, Joaçaba. 2014; 5(1): 41-48.

20. Vidal-Martins AMC, Burger KP, Aguilar CEG, Gonçalves ACS, Grisólio APR, Rossi GAM. Implantação e avaliação do programa de boas práticas de manipulação em açougues do Município de São José do Rio Preto - SP. Rev. Bras. Hig. Sanid. Anim 2014; 8:73-86.

21. Santana EHW, Beloti V, Aragon-Alegro LC, Mendonça MBOC. Estafilococos em alimentos Arq. Inst. Biol., São Paulo. 2010; Jul 77(3): 545-554.

22. Millezi AF, Tonial TM, Zanella JP, Moschen, EES, De Ávila CAC, Kaiser VLK, Hoffmeister S. Avaliação e qualidade microbiológica das mãos de manipuladores e do agente sanificante na indústria de alimentos. Universidade Regional e Integrada do Alto Uruguai e das Missões Campus de Frederico Westphalen, RS Ver. Analyt. 28, 2007.

23. Souza M, Pinto FGS, Bona EAM, Moura AC. Qualidade higiênicosanitária e prevalência de sorovares de Salmonella em linguiças frescais produzidas 51 artesanalmente e inspecionadas, comercializadas no oeste do Paraná, Brasil. Arquivos do Instituto Biológico. 2014; 81(2): 107-112.

24. Neres SL, Pacheco A.E, Junior LBJ, Joele PSRM. linguiça defumada elaborada com carne de búfalo: caracterização físico-química, microbiológica e sensorial. Rev. Bras. de Prod. Agroind. Campina Grande. 2014; 16(3):.273-278.

25. Marques SC, Boari CA, Brcko CC, Nascimento AR, Piccol RH. Avaliação higiênico-sanitária de linguiças tipo frescal comercializadas nos municípios de Três Corações e Lavras-MG. Ciênc. Agrotec 2006; 30:1120-23.

26. Morot-Bizot SC, Leroy S, Talon R. Staphylococcal community of a small unit manufacturing traditional dry fermented sausages. Int. J. Food Microbiol 2006; 108:210-217. 